\title{
Documentos
}

DURANTE EL DECIMO PERIODO DE SESIONES ORDINARIAS DE LA COMISIÓN DEL ACUERDO DE CARTAGENA, EL 17 DE NOVIEMBRE DE 1972, FUE INSTALADA LA COMISIÓN MTXTA ANDINO-ARGENTINA, QUE FUE ESTABLECIDA MEDIANTE UNA DECLARACIÓN CONJUNTA CONSTITUTIVA. EL SIGUIENTE ES EL TEXTO DEL. DOCUMENTO.

FL PROPÓSITO COMÚN DE FORTALECER IA INTEGRAGIÓN LATINOAMIERICANA

1) La Comisión del Acuerdo de Cartagena, integrada por los representantes plenipotenciarios de los gobiernos de las Repúblicas de Bolivia, Colombia, Chile, Ecuador y Perú por una parte, y el representante designado al efecto por el Gobierno de la República Argentina, por otra, inspirados en el propósito común de fortalecer e impulsar la integración de América Latina, como un medio para acelerar el desarrollo económico de sus países y mejorar los niveles de vida y bienestar. de sus pueblos, han convenido, luego de sucesivas reuniones preparatorias, constituir una Comisión, que en adelante se denominará Comisión Andino-Argentina, dentro del espiritu y los objetivos del Tratado de Montevideo y del Acuerdo de Cartagena.

2) La Comisión Andino-Argentina tendrá por objeto promover un mayor acercamiento entre los paises firmantes del Acuerdo de Cartagena y la República Argentina, en materia comercial, industrial y tecnológica asi como en otras áreas que permitan desarrollar políticas y acciones conjuntas de mutuo beneficio y analizar las posibịlidades de una complementación económica progresiva. Para ello, examinará las actuales relaciones, explorará los temas de especial interés para ambas partes y propondrá las medidas pertinentes.

3) La Comisión Andino-Argentina estará integrada por un representante de cada uno de los paises miembros del Acuerdo de Cartagena, por una parte, $y$ por un representante de Ia República Argentina por la otra. Estos representantes podrán, si lo estiman conveniente, asistir a las reuniones acompañados de sus asesores.

4) Los representantes de los países miembros del Acuerdo de Cartagena estarán asesorados por sus respectivos técnicos nacionales y por la Junta del Acuerdo de Cartagena. El representante argentino estará asesorado por los técnicos que su Gobierno designe al efecto.

5) La Comisión Andino-Argentina sesionará en la sede de la Junta del Acuerdo de Cartagena o en Buenos Aires, según se convenga en çada oportunidad.

6) La Comisión del Acuerdo de Cartagena y el representante de la Repú- 
blica Argentina acordarán, en cada caso, la fecha y el temario de las reuniones de la Comisión Andino-Argentina.

Todo intercambio de nota e información se producirá por intermedio de la Embajada Argentina en Lima.

7) La Comisión Andino-Argentina tendrá carácter consultivo y los acuerdos que adopte serán elevados como recomendaciones a las Partes.

\section{PRograma de acción CONJUNTA}

Con el objeto de llevar a la práctica los propósitos expresados en la declaración conjunta constitutiva de la Comisión Andino-Argentina, la Comisión del Acuerdo de Cartagena y el representante de la República Argentina convienen el presente programa de acción conjunta. Se incluyen en él las principales áreas en las que se considera están dadas las condiciones para la iniciación de los estudios respectivos, sin que ello tenga carácter limitativo con respecto a-otras áreas que la Comisión Andino-Argentina considere conveniente incorporar en el futuro. En los programas y estudios correspondientes, se tendrán especialmente en cuenta la participación e intereses de los países de menor desarrollo económico relativo.

1) Programas de desarrollo industrial: estudios conjuntos de los programas aprobados por el Grupo Andino para proponer medidas tendientes al abastecimiento mutuo de los productos involucrados. Análisis de las posibilidades de su perfeccionamiento mediante acuerdos de complementación en el marco de la ALALC.

2) Promover programas concretos en sectores especificos de interés mutuo, incluyendo eventualmente inversiones y aprovisionamiento de materias primas - con objeto de desarrollar fuentes productivas para mercados ampliados- especialmente en sectores asignados a los países de menor desarrollo económico relativo en el marco del Acuerdo de Cartagena.

3) Estudio de la participación de inversionistas y empresas argentinas en. los paises miembros del Acuerdo de Cartagena.

4) Promover la creación de empresas multinacionales andino-argentinas mediante el aporte de inversiones procedentes de los respectivos paises.

5) Financiamiento del comercio recíproco.

6) Intercambio permanente $y$ sistemático de información sobre patentes y marcas y en general sobre transferencia de tecnología.

6.1) diseño y creación de un sistema de información sobre patentes y marcas y sobre el proceso de transferencia de tecnología.

6.2) realización de un estudio conjunto del sistema de patentes en la Argentina $y$ en los países del Acuerdo de Cartagena.

6.3) investigación documental, técnica y de precios. Programas específicos de transferencia de información.

7) Programas conjuntos de investigación tecnológica y de adaptación de tecnologias importadas, en los siguientes campos, entre otros:

7.1) realización de programas de investigación para la formación de recursos 
humanos así como para la búsqueda y adaptación de nuevas técnicas agropecuarias aplicables a situaciones comunes;

7.2) tecnología de alimentos. Procesamiento industrial de productos alimenticios;

7.3) metrologia (mecánica, térmica y eléctrica). Cooperación técnica de la Argentina para posibilitax que los paises del Acuerdo de Cartagena puedan disponer sin mayores inversiones y a breve plazo de un sistema continental de calibración;

7.4) mineralurgia y metalurgia extractiva. Programas de cooperación tendientes a la formación de recursos humanos y a la realización de investigaciones conjuntas para el aprovechamiento de recursos naturales no renovables;

7.5) tecnología de comunicaciones. Programas de formación de personal $y$ de investigación operacional en institutos de investigación argentinos;

7.6) tecnología energética. Programas de formación de expertos en los laboratorios de las empresas argentinas del área energia;

7.7) tecnología hídrica. Programa de formación de técnicos en hidráulica aplicada en los laboratorios argentinos;

7.8) tecnologia de la construcción, relacionada con construcción de viviendas de interés social.

8) Mejoramiento de la infraestructura física.

9) Cooperación técnico-financiera con la Corporación Andina de Fomento. Entre otras acciones, establecimiento de líneas de crédito del Banco Central de la República Argentina,

La Comisión Andino-Argentina convino crear dos grupos de expertos que tendrán a su cargo el examen de las siguientes materias:

a) cooperación técnica; $y$

b) aspectos comerciales, industriales y financieros.

la primera reunión de los grupos de expertos se realizará en la ciudad de Buenos Aires. La fecha de las reuniones se determinará de conformidad con los procedimientos establecidos a esos efectos en la declaración conjunta constitutiva de la Comisión Andino-Argentina. A tal fin se indicó tentativamente que se podrían realizar en la segunda quincena del mes de marzo del año entrante [por 1973]. 